\title{
Effects of shading on spatial distribution of flower and flower abscission in field-grown three soybeans in Northern China
}

\author{
Liu Bing', Qu De-Ning ${ }^{2}$ \\ ${ }^{1}$ The College of Life Science, Jilin Normal University, Siping 136000, China; ${ }^{2}$ The College of Mathematics science, Jilin Normal University, \\ Siping 136000, China
}

\section{A B S T R A C T}

\begin{abstract}
A 2-year field experiment was conducted under natural light and shading conditions to examine the responses of spatial distribution of flower and flower abscission in three soybeans, and characteristics of flowering progress also was discussed. The results showed that responses to shading occurred proportionately across the main axis node positions despite the differences in the time of development of flower and pod between the high and low node positions. Reproductive organ of middle node was more sensitive than that of low and high node in single plant. Compared with that under natural light, shading increased flowering time 7 days for H339, 3 days for HN35 and 1 day for KN18. Flowering process showed a significant four stages: early-bloom phase (4-6 days), full-bloom phase (about 15 days), slow-bloom phase (about 10 days) and final-bloom phase (about 9-16 days). Soybean has the characteristic of excessive flower production. Our data may give a hint that flower number produced per plant isn't uppermost factor determining in final pod number survived per plant. Excessive flower produced per plant maybe just is precondition as reproductive prosperity in soybean.
\end{abstract}

Keywords: Shading; Pod number; Node number; Flower abscission

\section{INTRODUCTION}

Environmental conditions prevailing during the reproductive period are important determinants of soybean yield and yield components (Board and Harvill et al., 1996; Liu et al., 2010; Liu et al., 2013). Board and Harvill (1996) suggested that intensity and quality of solar radiation intercepted by the canopy influenced yield by changing survival rate of flowers in soybean plant. Liu et al (2010) stated that light enrichment and shading significantly decreased and increased abortive rate of flower resulting in change of pod number per plant. Umezaki and Yoshida (1992) indicated that plant height of soybean will increase with the decrease of light intensity.

Much of the soybean yield variation is related to changes in flower number that survived to mature. From 32 to $81 \%$ of the flowers of field-grown soybean do not develop into mature pods (Wiebold et al., 1981).

Flowering in soybean is a dynamic system in which flower survival may depend on where a flower is located and when it is initiated. Egli and Bruening (2006b) stated that the temporal distribution of flower and pod production plays an important role in determining pod or seed number at maturity. Both of flowering and pod production periods at individual node continue for 30 days or more, and they are nearly same long (Huff and Dybing, 1980; Gai et al., 1984; Egli and Bruening, 2006b). The timing of a flower initiate during the bloom or seed-filling period was important and that late developing flowers may abort because large rapidly growing pods and seeds from early flowers consume most of the assimilate (Bruening and Egli, 2000).

Most flowers are produced in a much shorter time compared to total reproductive period (Kuroda et al., 1998). Flowering on whole plants includes inter- and intra nodal variation, and there is 15-50 days interval between the first and last flowers (Gai et al., 1984; Constable and Ross, 1988; Dybing, 1994; Zheng et al., 2002). The node location of a flower in soybean main axis determines, in part, when it develops. This time of a flower developing is a critical factor in determining it survival or abscission, because at

\footnotetext{
${ }^{*}$ Corresponding author:

Liu Bing, The College of Life Science, Jilin Normal University, Siping 136000, China. E-mail: liubing3562@126.com
} 
individual node, the abortion of early developing flowers always had lower than those developing later (Brun and Betts, 1984; Heitholt et al., 1986).

Soybean plants have highly asynchronous flowering characteristic and the degree of asynchrony may determine, in part, soybean growth character (determinate and indeterminate). This phenomenon often occurs in soybean certain node of main stem; some pods were filling however flowering still continues. Huff and Dybing (1980) indicated that flowering at individual nodes usually starts at the base of the primary raceme and continues upward with about 1-day intervals between flowers. Flowering on the higher order racemes or sub-branches usually starts after the primary raceme (Munier-Jolain et al., 1994; Saitoh et al., 1998; Egli and Bruening, 2002; Zheng et al., 2002). In soybean plants, when the lowermost nodes start filling seeds, the uppermost nodes are still in the process of producing flowers. Whether from the single plant level or an individual node, the abscission of late developing flowers mostly are inevitable when a large number filling pod exist.

Although effects of environmental factors on flowering and pod reproduction patterns have been reported (Dybing, 1994; Nakamoto et al., 2001; Zheng et al., 2002, Liu et al., 2010), little information is available for the distribution of flower abscission across main axis under shading condition. More detailed research still need to analyze effect of environmental condition on flower abscission. Our objective of the current research was to investigate the responses of spatial distribution of flower and flower abscission across the main axis to shading in field-grown three soybeans.

\section{MATERIALS AND METHODS}

\section{Site description}

A 2-year filed study was conducted in 2011 and 2012 in Agricultural experiment station of Jilin Normal University, China. The research site is in the north temperate zone and continental monsoon area (cold and arid in winter, hot and rainy in summer), has an average annual precipitation of $573 \mathrm{~mm}$, and an average annual temperature of $5.9^{\circ} \mathrm{C}$. Annual sunshine is around $2679 \mathrm{~h}$, total annual solar radiation is $124 \mathrm{M} \mathrm{J} \mathrm{cm}^{-2}$ and annual average available accumulated temperature $\left(\geq 10{ }^{\circ} \mathrm{C}\right)$ is $3079{ }^{\circ} \mathrm{C}$. The area is the typical Mollisol (Black soil) region and the textural class of the Black soil is silty clay loam.

\section{Cultural practice}

Three sub-determinate soybean cultivars were used in the experiment. They were Hai339 (H339), Heinong35 (HN35), and Kennong18 (KN18). In 2011 and 2012, a random complete block experimental design with three replications was used. Soybean cultivars Hai339, Heinong 35 and Kennong18 were planted in 14 plants $\mathrm{m}^{-2}$. Seeds were sown on 6 May 2011 and 8 May 2012. Three soybean cultivars (Hai339, Heinong35 and Kennong18) were planted and precision drilling, ridge tillage was used. The ridge distance is $0.67 \mathrm{~cm}$. Carbamide $50 \mathrm{~kg} \mathrm{ha}^{-1}(\mathrm{~N} 46 \%)$, and diammonium phosphate of $50 \mathrm{~kg} \mathrm{ha}^{-1}(\mathrm{~N} 18 \%$, $\mathrm{P}_{2} \mathrm{O}_{5} 46 \%$ ), and composite fertilizer of $150 \mathrm{~kg} \mathrm{ha}^{-1}(\mathrm{~N} 18 \%$, $\mathrm{P}_{2} \mathrm{O}_{5} 16 \%, \mathrm{~K}_{2} \mathrm{O} 16 \%$ ) were applied before seeding. The weeds were controlled by hand. Usual field management was followed. In particular, appropriate water management measures to be implemented. The growth of soybean isn't suppressed in field conditions.

\section{Shading treatment}

Shading was provided by black polypropylene fabric installed $0.5 \mathrm{~m}$ above the soybean canopy. Shade cloth was attached to metallic posts, which resulted in $25 \%$ light reduction compared to the ambient light. Shading treatment was implemented at late vegetative stage, which is the growth stage V5 (Fehr and Caviness, 1977), and were left in place for the remainder of the growing season. These treatments will not result in big changes for canopy temperature, humidity as well as air circulation.

\section{Data collect and statistical analysis}

In each plot, 15 plants were allocated and tagged randomly to each treatment. From first flower to last flower period, new flowers in every day was marked with acrylic paint on the pedicel and base of the flower. Information of flower number and node position were recorded. We used pod number at mature period showed successful flower number these survive to become pods. Young pod abscission also is expression of flower abort. For each group of plants these tagged, data were recorded according to node position on the main axis and for each branch corresponding to the main axis node from which it arose. Node 1 was the unifoliate node, being the first node above the cotyledons. Statistical analysis of data was performed by using PROC ANOVA (analysis of variance), and Duncan's multiple range tests were used for mean comparison (SAS Institute, Inc. 1996).

\section{RESULTS AND DISCUSSION}

\section{Spatial distribution of flower/pod across the main axis under shade}

Shading treatments resulted in proportional change in flower/pod number cross all node positions (Fig. 1). Profiles for pods per node were similar to profiles for flowers in three soybeans. This is true for three cultivars. Most flowers and pods were produced at the nodes in the middle parts 

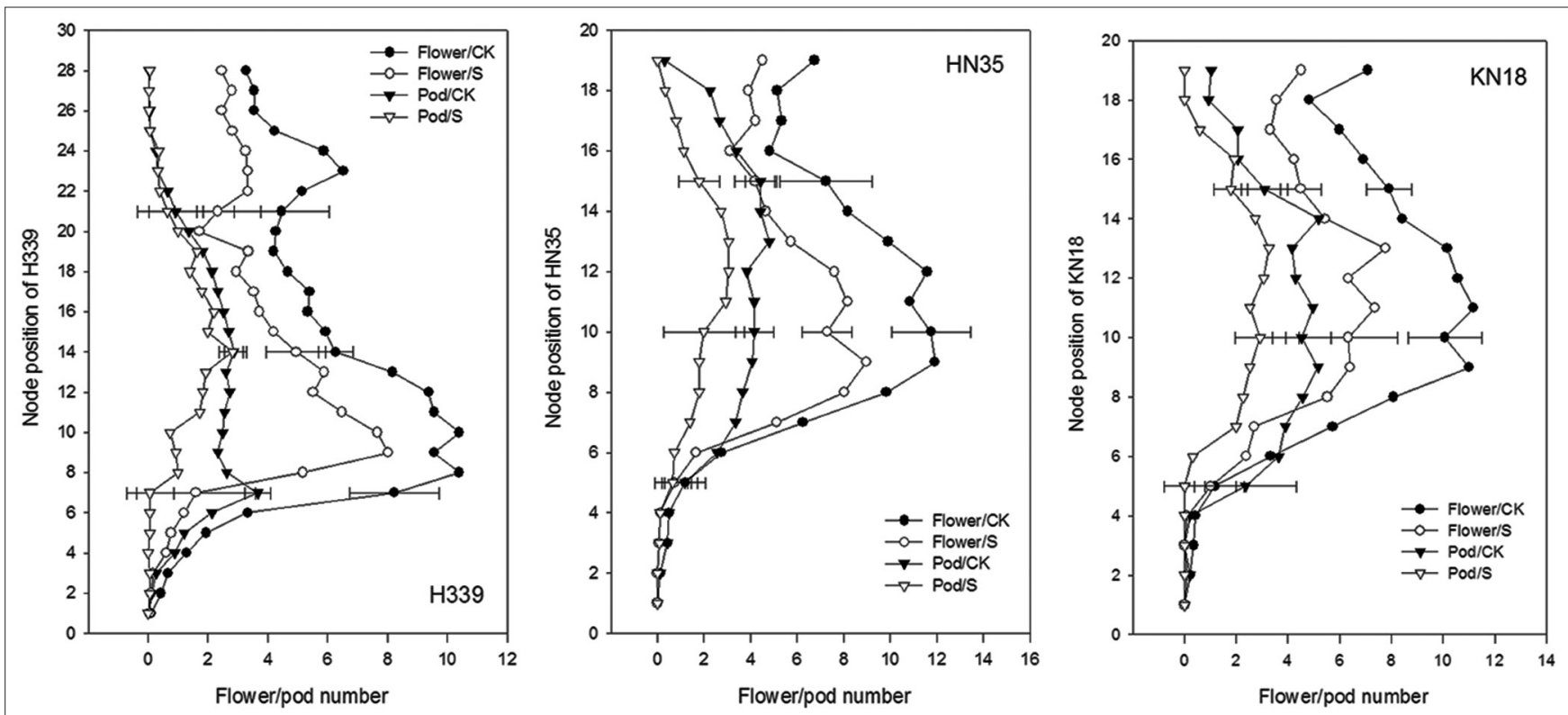

Fig 1. Distribution of flower/pod number in the main stem of three cultivars treated with shading. H339, HN35 and KN18 are Hai339, Heinong35 and Kennong18, respectively. CK and S are natural light and shade treatment. Bar indicates standard error of the mean.

of the plants. Flower abscission in middle nodes of main stem in soybean accounts for $50 \%$ of total abscission (Zhao et al., 2013). Intense competition of assimilates is maybe important reason, and abnormal flower abscission also was closely with rainfall weather. Differences in flower and pod distribution curve between cultivars were observed. The space among flower distribution curves in HN35 and KN18 cultivars was wider than $\mathrm{H} 339$ cultivar. This indicated that shading had much stronger effect on flower number per node in main axis of two cultivars (HN35 and KN18) than that of H339 cultivar. This decrease in flowers due to shading occurred relatively consistent across every node in the main axis. This showed that shading initiated from the late vegetative stage influenced the final flower number through changing flower abscission at all nodes. Heindl and Brun (1984) reported that there is only a slight variation in the number of flowers formed at each node, and high rate of flower abscission was the major factor determining pod number per node. Our data suggested that environmentally induced variation in pod number in soybean could be a result of changes in number of flowers produced. Pod number per plant was the most responsible component for yield change under shading. Shading imposed late vegetative stage would change assimilates availability to the developing reproductive structures, influence flowering, and flower and pod abscission number at harvest. Pod number per plant as the yield component was most influenced by change in cultural and environmental conditions (Herbert and Litchfield, 1982; Board et al., 1992)

Heindl and Brun (1984) reported little variation in flowers per node on the main stem of a MG 0 cultivar. The different effect of the shade treatments varied among genotypes. Sharma et al. (1996) indicated that there is genotypic variation in flowers per node. $\mathrm{N}$ nutrition treatments altered flower abscission but did not affect flowers per node. In my experiment, shade induced decrease in pod number per node, however shade influence more in flower number per node. That is a possible reason that production of a flower need less assimilates than pod growth (include seed filling) and changes flower number is much easier than abscission of pod number. In general, it is impossible that flower abscission is completely avoided. Flower abscission is expression of biological adaptability of soybean. Reducing of abnormal flower abscission was achieved by improving soil fertility, appropriate density and other effective technical measures.

Egli and Bruening (2006a) indicated that pods reaching maximum length always have high possibility of survival under shade. Pod survival and abscission at individual nodes is relatively independent of the photosynthesis of the subtending leaf, but the interaction among early and late pods is strictly an intra-nodal phenomena. CharlesEdwards (1984) proposed an elegant model that describes the number of vegetative or reproductive meristems per unit area as a direct function of assimilate availability and inversely related to the minimum flux of assimilate required to maintain a meristem. That is true that flowers production is continuous from R1 to R5 or later. Assimilate availability may have to be defined on an individual node basis at a function of time, surely a significant increase in complexity. Our research may give a hint that reproductive organ of middle node was more sensitive than that of low and high 
node in single plant. Soybean can perceive this signal of lower photosynthate environment and make plant itself produce fewer flowers per node.

\section{Characteristics of flowering progress in three soybeans under shading}

Regardless of cultivars and light treatment, the new flower number produced every day in total flowering period showed a one-peak curve, i.e. highest value were observed at about 7 9 flowers from July 20 to July 28, and then declined to 0.5 flowers at about August 20 (Fig. 2). Continuous shade affected the length of the pod production period (Egli and Bruening, 2005). Shading increased flowering time. Compared with that under natural light, the flowering time increased 7 days for $\mathrm{H} 339,3$ days for HN35 and 1 day for KN18 under shade (Table 1). Long period of pod production and pod set in soybean may help stabilize pod number in fluctuating environments (Egli and Bruening, 2005).

Generally, flowering process showed significant four different phases: early-bloom phase (first phase: from July 6 to July 12); Full-bloom phase (second phase: from July 13 to July 28); Slow-bloom phase (third phase: from July 29 to August 6); final-bloom phase (fourth phase: from August 7 to August 23).
Early-bloom phase is short (only 4-6 days), less than 4 flowers per day. Under natural light and shade, the total flower number at this stage for three cultivars is only 8.67 and 5.27 , and they account for $5.88 \%$ and $5.89 \%$ respectively.

Full-bloom phase is longer than other phases, and it is about 15 days. Under natural light and shading, average 6.56 and 4.37 flowers everyday was produced for H339; 4.75 and

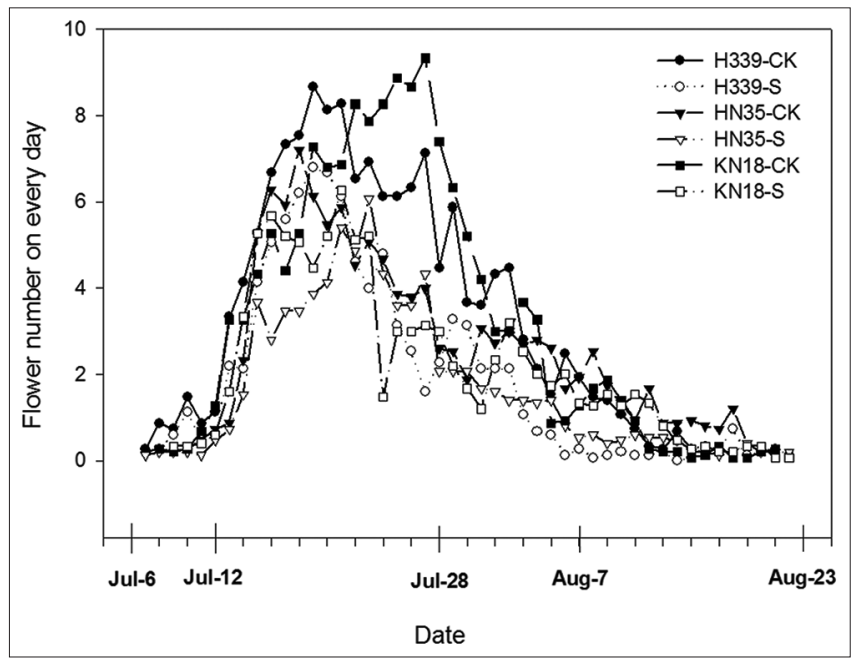

Fig 2. The flowering amount per plant in three cultivars on everyday. H339, HN35 and KN18 are Hai339, Heinong35 and Kennong18, respectively. $\mathrm{CK}$ and $\mathrm{S}$ are natural light and shade treatment.

Table 1: Flowering characteristics in three cultivars at different bloom phases

\begin{tabular}{|c|c|c|c|c|c|c|}
\hline Variety & Flowering stage & Date & Range/flower & Total flower & Flower per day & Percentage/flower \\
\hline \multirow[t]{4}{*}{ H339(CK) } & Early bloom phase & $7.6-7.12$ & $0.27-3.33$ & 8.67 & 1.24 & 5.88 \\
\hline & Full bloom phase & $7.13-7.28$ & $4.13-8.67$ & 105.52 & 6.60 & 71.62 \\
\hline & Slow bloom phase & $7.29-8.7$ & $1.47-4.47$ & 28.40 & 2.84 & 19.28 \\
\hline & Final bloom phase & 8.8-8.14 & $0.27-1.40$ & 4.74 & 0.68 & 3.22 \\
\hline \multirow[t]{4}{*}{ H339(S) } & Early bloom phase & 7.7-7.12 & $0.27-2.20$ & 5.27 & 0.88 & 5.89 \\
\hline & Full bloom phase & $7.13-7.28$ & $1.60-6.80$ & 68.93 & 4.31 & 77.04 \\
\hline & Slow bloom phase & $7.29-8.7$ & $0.07-3.13$ & 12.33 & 1.23 & 13.78 \\
\hline & Final bloom phase & $8.8-8.21$ & $0.00-0.73$ & 2.92 & 0.21 & 3.26 \\
\hline \multirow[t]{4}{*}{ HN35(CK) } & Early bloom phase & 7.6-7.12 & $0.20-0.87$ & 3.01 & 0.43 & 2.62 \\
\hline & Full bloom phase & 7.13-7.28 & $2.33-7.20$ & 75.54 & 4.72 & 65.76 \\
\hline & Slow bloom phase & $7.29-8.7$ & $1.67-3.07$ & 24.87 & 2.49 & 21.65 \\
\hline & Final bloom phase & 8.8-8.18 & $0.40-1.73$ & 11.46 & 1.04 & 9.98 \\
\hline \multirow[t]{4}{*}{ HN35(S) } & Early bloom phase & 7.6-7.12 & $0.13-0.73$ & 2.06 & 0.29 & 2.61 \\
\hline & Full bloom phase & $7.13-7.28$ & $1.53-6.07$ & 59.28 & 3.71 & 75.16 \\
\hline & Slow bloom phase & $7.29-8.7$ & $0.53-2.07$ & 12.80 & 1.28 & 16.23 \\
\hline & Final bloom phase & $8.8-8.21$ & $0.13-0.60$ & 4.73 & 0.34 & 6.00 \\
\hline \multirow[t]{4}{*}{ KN18(CK) } & Early bloom phase & 7.7-7.12 & $0.20-3.27$ & 5.95 & 0.99 & 4.03 \\
\hline & Full bloom phase & $7.13-7.28$ & $3.27-9.33$ & 108.49 & 6.78 & 73.57 \\
\hline & Slow bloom phase & $7.29-8.7$ & $0.87-5.20$ & 27.08 & 2.71 & 18.36 \\
\hline & Final bloom phase & $8.8-8.20$ & $0.07-1.87$ & 6.01 & 0.46 & 4.08 \\
\hline \multirow[t]{4}{*}{ KN18(S) } & Early bloom phase & $7.8-7.12$ & $0.33-1.60$ & 3.26 & 0.65 & 3.33 \\
\hline & Full bloom phase & $7.13-7.28$ & $1.47-6.27$ & 66.61 & 4.16 & 68.06 \\
\hline & Slow bloom phase & $7.29-8.7$ & $1.20-3.20$ & 19.26 & 1.93 & 19.68 \\
\hline & Final bloom phase & $8.8-8.21$ & $0.07-1.53$ & 8.73 & 0.62 & 8.92 \\
\hline
\end{tabular}

H339, HN35 and KN18 are Hai339, Heinong35 and Kennong18, respectively. CK and S are natural light and shade treatment. Date: From the start of this phase to the end of this phase. Range/flower: The range of the flower number per individual plant per day. Total flower: The total flower number on this stage. Flower per day: The average flower number per day on this stage. Percentage/flower: The percentage of the flower number at certain flowering stage (\%) 
3.72 for HN35; 6.54 and 4.20 for KN18. Compared with other phases, most flowers were produced in this phase. Regardless of light treatment, average $74.33 \%$ flower was produced in full-bloom phase for $\mathrm{H} 339 ; 70.46 \%$ for HN35; 70.82\% for KN18. Gai et al. (1984) indicated that $70 \%$ flowers were produced in full-bloom phase, however early-bloom and full-bloom phase can't exactly reflect quantity characteristic of flowers. How much produced and abscission of flower in soybean is related with character of cultivars (Hu and Lin, 2009). Environmental factors such as density, soil, climate and disease were closely related with flower number of soybean.

Slow-bloom phase was much shorter than full-bloom phase, and it is only 10 days. Flowers number produced in a day decreased dramatically to $0.13 \sim 2.47$ at August 5 . Regardless of light treatment, average $16.53 \%$ flower was produced in slow-bloom phase for H339; $18.94 \%$ for HN35; 19.02\% for KN18. Chen et al. (1998) suggested that flowering number of soybean had the characteristics of normal distribution.

Final-bloom phase was longer than early- and slow-bloom phase. In particular, there was nearly 9-16 days for three cultivars under shading; however less flower number was produced in this phase. Under natural light and shading, there was average 0.90 and 0.20 flower number produced in a day for H339, 1.22 and 0.37 for $\mathrm{HN} 35,0.60$ and 0.71 for KN18.

\section{Effect of shade on flower, pod number and yield in three soybeans}

Shade significantly decreased flower number per plant compared with that of the ambient light. Shade decreased Hai339 (H339) flower number per plant by 39.3\%; that of Heinong35 (HN35) by $31.3 \%$ and that of Kennong18 (KN18) by 33.6\%, respectively (Table 2 ).

Pod number per plant as the yield component was the most influenced by change in cultural and environmental conditions (Board and Tan 1995; Egli, 2005).

Kakiuchi and Kobata (2004) indicated pod number per plant gradually decreased with the increase of shade intensity, and seed number per pod also significantly decreased under heavy shade. Shade influenced accumulation process of fatty acids and composition of fatty acids significantly (Liu et al., 2009).

In our research, shade decreased pod number per plant $44.3 \%$ for $\mathrm{H} 339,42.4 \%$ for $\mathrm{KN} 35,50.7 \%$ for $\mathrm{KN} 18$. There is only a slight variation in the number of flowers formed at each node, and high rate of flower abscission was the major factor determining the pod number per node (Heindl and Brun, 1984). The reduction in pods under shade was a result of fewer flowers per plant and an increase in flower and pod abscission. Whether light influence on final pod number is mainly from variation of flower or change of young pod abscission is still unclear (Liu et al., 2010). From our experiment, this is clear that flower number produced isn't major factor determining final pod number at physiological mature. Soybean always has the characteristic of excessive flower production. The relative importance of changes in number of flowers per plant vs. abscission percentage varied across cultivars, treatments, and years, but clearly both processes were involved in determining final pod number. However, Hardman and Brun (1971) stated that pod production was often more important than pod abortion in determining mature pod number.

Under natural light and shade, there is nearly flower abscission rate, and they were $72 \%$ and $74 \%$ respectively. In this research, we think that the abscission of young pod is included within the flowers abscission. For HN35 and KN18, there was higher flower abscission under shade than that under natural light. This phenomenon maybe is much related with cultivar characteristic. Different cultivar had different sensitivity to light treatment. Shade decreased yield per plant $35.5 \%$ for $\mathrm{H} 339,42.4 \%$ for HN35, 51.8\% for KN18. Shading resulted in lengthening of internodes, decreasing of the number of pods and seeds per plant, the seeds yield per plant, the aerial part biomass per plant significantly (Ephrath et al., 1993, Umezaki and Yoshida, 1992). The impact of shading on seed yield depends on duration of shading (Jiang and Egli, 1995).

To some extent, mildly shade can simulate the premature closure of soybean population. Early soybean population closure influences the quality characters of fatty acids (Liu et al., 2009). Different planting density determines the time of the soybean canopy closure. Planting density also has obviously effect on the spatial and temporal distribution characteristics of pod production in soybean. Adding the temporal distribution of pod production and survival to

Table 2: Effect of shading on flower, pod number, flower abscission and yield in three soybeans

\begin{tabular}{llcccc}
\hline Cultivar & Treatment & $\begin{array}{c}\text { Flowers } \\
\text { (no. } \\
\text { plant }^{-1} \text { ) }\end{array}$ & $\begin{array}{c}\text { Pods } \\
\text { (no. }^{\text {plant }}{ }^{-1} \text { ) }\end{array}$ & $\begin{array}{c}\text { Abscission } \\
(\%)\end{array}$ & $\begin{array}{c}\text { Yield } \\
\text { (g.plant }^{-1} \text { ) }\end{array}$ \\
\hline H339 & CK & $147.3 \mathrm{a}$ & $41.8 \mathrm{a}$ & $72 \mathrm{a}$ & $24.8 \mathrm{a}$ \\
& Shade & $89.4 \mathrm{~b}$ & $23.3 \mathrm{~b}$ & $74 \mathrm{a}$ & $16.0 \mathrm{~b}$ \\
$\mathrm{HN} 35$ & CK & $114.9 \mathrm{a}$ & $48.4 \mathrm{a}$ & $58 \mathrm{a}$ & $17.2 \mathrm{a}$ \\
& Shade & $78.9 \mathrm{~b}$ & $26.4 \mathrm{~b}$ & $67 \mathrm{~b}$ & $9.9 \mathrm{~b}$ \\
$\mathrm{KN} 18$ & CK & $147.5 \mathrm{a}$ & $52.7 \mathrm{a}$ & $64 \mathrm{a}$ & $17.0 \mathrm{a}$ \\
& Shade & $97.9 \mathrm{~b}$ & $26.0 \mathrm{~b}$ & $73 \mathrm{~b}$ & $8.2 \mathrm{~b}$ \\
\hline
\end{tabular}

H339, HN35 and KN18 are Hai339, Heinong35 and Kennong18, respectively. CK and $\mathrm{S}$ are natural light and shade treatment. Different letters within the row represent significantly different from natural light and shading under same cultivar $(P<0.05)$ 
models predicting pod and seed number will improve their accuracy (Egli and Bruening, 2005). From spatial distribution of flowers across main axis in soybean, our data may propose that flower number produced per plant isn't uppermost factor determining in final pod number survived per plant. Excessive flower produced per plant maybe is precondition as reproductive prosperity in soybean.

\section{CONCLUSION}

Reproductive organ of middle node was more sensitive than that of low and high node in single soybean plant. Shading increased flowering time for three soybeans in our experiment. Flowering process of soybean have four stages: early-bloom phase, full-bloom phase, slow-bloom phase and final-bloom phase. Soybean plant has the characteristic of excessive flower production. Excessive flower produced per plant only is precondition as reproductive prosperity, that is say flower number isn't uppermost factor determining in final survived pod number. Environmental conditions are uppermost factors determining in final survived flower and pod number. Excessive flower produced per plant only provides a basic precedent condition.

\section{ACKNOWLEDGMENT}

This research was supported by a grant from the Science and Technology Development Program of Jilin Province (20140411011XH), the starting foundation for doctor of Jilin Normal University (2010020) and Project funded by china postdoctoral science foundation (Y5Q2031100).

\section{Author contributions}

L. B. designed and implemented the study, wrote the article and Q. D. $\mathrm{N}$ did the analysis and corrected the article.

\section{REFERENCES}

Board, J. E. and B. G. Harville. 1996. Growth dynamics during the vegetative period affects yield of narrow-row, late-planted soybean. Agron. J. 88: 567-572.

Board, J. E., M. Kamal and B. G. Harville. 1992. Temporal importance of greater light interception to increased yield in narrow-row soybean. Agron. J. 84: 575-579.

Board, J. E. and Q. Tan. 1995. Assimilatory capacity effects on soybean yield components and pod number. Crop Sci. 35: 846-851.

Bruening, W. P. and D. B. Egli. 2000. Leaf starch accumulation and seed set at phloem-isolated nodes in soybean. Field Crops Res. 68: $113-120$.

Brun, W. A. and K. J. Betts. 1984. Source/sink relations of abscising and non-abscising soybean flowers. Plant Physiol. 75: 187-181.

Charles-Edwards, D. A. 1984. On the ordered development of plants. I. An hypothesis. Ann Bot. 53: 699-707.

Chen, J. M., J. Z. Zhao and F. R. Yang. 1998. Effect of sowing dates on blooming model and grain yield of soybean. Soybean Sci. 17: 225-229.

Constable, G. A. and I. A. Ross. 1988. Variability of soybean phenology response to temperature, daylength and rate of change in daylength. Field Crops Res. 18: 57-69.

Dybing, C. D. 1994. Soybean flower production as related to plant growth and seed yield. Crop Sci. 34: 489-497.

Egli, D. B. and W. P. Bruening. 2006a. Fruit development and reproductive survival in soybean: Position and age effects. Field Crops Res., 98: 195-202.

Egli, D. B. and W. P. Bruening. 2002. Flowerjing and fruit set dynamics during synchronous flowering at phloem-isolated nodes in soybean. Field Crops Res. 79: 9-19.

Egli, D. B. and W. P. Bruening. 2005. Shade and temporal distribution of pod production and pod set in soybean. Crop Sci. 45: 1764-1769.

Egli, D. B. and W. P. Bruening. 2006b. Temporal profiles of pod production and reproductive success in soybean. Eur. J. Agron. 24: 11-18.

Egli, D. B. 2005. Flowering, pod set and reproductive success in soybean. J. Agron. Crop Sci. 191: 283-291.

Ephrath, J. E., R. F. Wang, K. Terashima, J. D. Hesketh, M. G. Huck and J. W. Hummel. 1993. Shading effects on soybean and corn. Biotronics. 22: 15-24.

Fehr, E. R. and C. E. Caviness. 1977. Stage of soybean development. lowa State University, Special Report. No. 80, American, IA.

Gai, J., Palmer, R. G and W. R. Fehr. 1984. Bloom and pod set in determinate and indeterminate soybeans grown in China. Agron. J. 76: 979-984.

Hardman, L. L. and W. A. Brun. 1971. Effects of atmospheric carbon dioxide enrichment at different development stages on growth and yield components of soybeans. Crop Sci. 11: 886-888.

Heindl, J. C. and W. A. Brun. 1984. Pattern of reproductive abscission, seed yield, and yield components in soybean. Crop Sci. 24: 542-545.

Heitholt, J. J., D. B. Egli and J. E. Leggett. 1986. Characteristics of reproductive abortion in soybean. Crop Sci. 26: 589-595.

Herbert, S. J. and G. V. Litchfield. 1982. Partitioning soybean yield components. Crop Sci. 22: 1074-1079.

Hu, R. F. and G. Q. Lin. 2009. The relationship between the flower and pod abscission rate of vegetable soybean and the reproductive stage of species. Chinese Agric. Sci. Bull. 25: 108-109.

Huff, A. and C. D. Dybing. 1980. Factors affecting shedding of flowers in soybean (Glycine max (L.) Merrill). J. Expt. Bot. 31: 751-762.

Jiang, H. and D. B. Egli. 1995. Soybean seed number and crop growth rate during flowering. Agron. J. 87: 264-267.

Kakiuchi. J. and T. Kobata. 2004. Shading and thinning effects on seed and shoot dry matter increase in determinate soybean during the seed filling period. Agron. J. 96: 398-405.

Kuroda, T., K. Saitoh, T. Mahmood and K. Yanagawa. 1998. Differences in flowering habit between determinate and indeterminate types of soybean. Plant Prod. Sci. 1: 18-24.

Liu, B., X. B. Liu, Y. S. Li and S. J. Herbert. 2013. Effect of enhanced UV-B radiation on seed growth characteristics and yield components in soybean. Field Crops Res. 154: 158-163.

Liu, B., X. B. Liu, C. Wang, Y. S. Li, J. Jin and S. J. Herbert. 2010. Soybean yield and yield component distribution across the main axis in response to light enrichment and shading under different densities. Plant Soil Environ. 56: 384-392.

Liu, B., C. Wang, J. Jin, J. D. Liu, Q. Y. Zhang, X. B. Liu and S. J. Herbert. 2009. Effects of shade during reproductive stage on 
accumulation of fatty acids in soybean seed. Soybean Sci. 28: 53-58.

Munier-Jolain, N. G., B. Ney and C. Duthion. 1994. Reproductive development of an indeterminate soybean as affected by morphological position. Crop Sci. 34: 1009-1013.

Nakamoto, H., S. H. Zheng, T. Furuya, K. Tanaka, A. Yamazaki and M. Fukuyama. 2001. Effects of long-term exposure to atmospheric carbon dioxide enrichment on flowering and podding in soybean. J. Fac. Agric. Kyushu Univ., 46: 23-29.

Saitoh, K., M. Kimura and T. Kuroda. 1998. Effects of isolation treatment of a node on flowering and pod set in field grown soybean. Jpn. J. Crop Sci. 67: 337-341.

SAS Institute, Inc. 1996. SAS/STAT User's Guide Release 6.09. SAS Institute, Inc., Cary, NC, USA.

Sharma, K., N. Walia, K. Sharma and N. Walia. 1996. Growth and yield of soybean Glycine max (L.) Merrill. as influenced by light intensity and cytokinin. Indian Agric. 39: 253-257.

Umezaki, T. and T. Yoshida. 1992. Effect of shading on the internode elongation of late maturing soybean. J. Fac. Agric. Kyushu Univ. 36: 267-272.

Wiebold, W. J., Ashley, D. A and H. R. Boerma. 1981. Reproductive abscission levels and patterns for eleven determinate soybean cultivars. Agron. J. 73: 43-46.

Zhao, S. J., X. D. Tang, X. Zhao, Y. Feng, C. C. Zhao and M. C. Zhang. 2013. Observation and research on the temporal and spatial distribution of flowering and flower dropping of soybean. Sci. Agric. Sin. 46: 1543-1554.

Zheng, S. H., H. Nakamoto, K. Yoshikawa, T. Furuya and M. Fukuyama 2002. Influences of high night temperatures on flowering and pod setting in soybean. Plant Prod. Sci. 5: 215-218. 